\title{
TGF $\beta /$ cyclin D1/Smad-mediated inhibition of BMP4 promotes breast cancer stem cell self-renewal activity
}

\author{
Gang Yan ${ }^{1}$, Meiou Dai ${ }^{1}$, Chenjing Zhang ${ }^{1,2}$, Sophie Poulet ${ }^{1}$, Alaa Moamer ${ }^{1}$, Ni Wang ${ }^{1}$, Julien Boudreault ${ }^{1}$,
} Suhad Ali (i) ${ }^{1}$ and Jean-Jacques Lebrun (i) ${ }^{1}$

\begin{abstract}
Basal-like triple-negative breast cancers (TNBCs) display poor prognosis, have a high risk of tumor recurrence, and exhibit high resistance to drug treatments. The TNBC aggressive features are largely due to the high proportion of cancer stem cells present within these tumors. In this study, we investigated the interplay and networking pathways occurring between TGF $\beta$ family ligands in regulating stemness in TNBCs. We found that TGF $\beta$ stimulation of TNBCs resulted in enhanced tumorsphere formation efficiency and an increased proportion of the highly tumorigenic CD44 $4^{\text {high }} / \mathrm{CD}_{2} 4^{\text {low }}$ cancer stem cell population. Analysis of the TGF $\beta$ transcriptome in TNBC cells revealed bone morphogenetic protein4 (BMP4) as a main TGF $\beta$-repressed target in these tumor cells. We further found that BMP4 opposed TGF $\beta$ effects on stemness and potently decreased cancer stem cell numbers, thereby acting as a differentiation factor in TNBC. At the molecular level, we found that TGF $\beta$ inhibition of BMP4 gene expression is mediated through the Smad pathway and cyclin D1. In addition, we also found BMP4 to act as a pro-differentiation factor in normal mammary epithelial cells and promote mammary acinar formation in 3D cell culture assays. Finally, and consistent with our in vitro results, in silico patient data analysis defined BMP4 as a potential valuable prognosis marker for TNBC patients.
\end{abstract}

\section{Introduction}

Triple-negative breast cancers (TNBCs) represent $10-20 \%$ of all breast cancers and are characterized by negative or low estrogen receptor (ER), progesterone receptor (PR), and human epidermal growth factor receptor 2 (HER2) expression ${ }^{1}$. Based on their gene expression profiles, the majority of TNBCs are classified as basal-like breast cancers. This molecular subtype is often associated with larger tumor size, higher tumor grade, greater lymph node spread, and a higher rate of distant metastasis ${ }^{2,3}$. Classification based on gene expression analyses revealed that TNBC can be

\footnotetext{
Correspondence: Jean-Jacques Lebrun (JJ.Lebrun@mcgill.ca)

${ }^{1}$ McGill University Health Center, Department of Medicine, Cancer Research Program, Montreal, QC H4A 3J1, Canada

²Department of Gastroenterology, Zhejiang Provincial People's Hospital,

People's Hospital of Hangzhou Medical College, Hangzhou, Zhejiang, China
}

categorized into six subgroups, including basal-like (BL1 and BL2), mesenchymal (M), mesenchymal stem-like (MSL), immunomodulatory (IM), and luminal androgen receptor $(\mathrm{LAR})^{1}$. The basal-like (BL1 and BL2) subtypes are highly enriched in gene expression patterns associated with proliferation and DNA damage-related genes while the mesenchymal ( $M$ and MSL) subtype shows high expression of epithelial-to-mesenchymal transitionrelated genes ${ }^{1,4}$. The immunomodulatory subtype presents gene ontologies for immune cell processes, including cytokine signaling as well as antigen processing and presentation $^{5,6}$. Finally, the LAR subtype shows enrichment in genes related to the androgen receptor (AR) signaling and has been associated with a better prognosis compared to other TNBC subtypes ${ }^{7,8}$. Despite initial response to adjuvant chemotherapy, TNBC patients typically develop distant recurrence within 5 years of

\section{(c) The Author(s) 2021}

(c) Open Access This article is licensed under a Creative Commons Attribution 4.0 International License, which permits use, sharing, adaptation, distribution and reproduction cc) in any medium or format, as long as you give appropriate credit to the original author(s) and the source, provide a link to the Creative Commons license, and indicate if changes were made. The images or other third party material in this article are included in the article's Creative Commons license, unless indicated otherwise in a credit line to the material. If material is not included in the article's Creative Commons license and your intended use is not permitted by statutory regulation or exceeds the permitted use, you will need to obtain permission directly from the copyright holder. To view a copy of this license, visit http://creativecommons.org/licenses/by/4.0/. 
diagnosis $^{3}$. Due to the molecular heterogeneity of TNBC and the absence of well-defined molecular targets, efficacious treatments for TNBC patients remain largely unavailable. Cancer stem cells (CSCs) or tumor-initiating cells represent a distinct subpopulation of cancer cells within the tumor, that possess stem cell-like properties ${ }^{9}$. These cells exhibit a long-term, self-renewal capacity, and can divide through asymmetric division, thereby continuously regenerating and propagating the heterogenous tumor $^{10}$. CSCs have been implicated in tumor growth and progression, drug resistance, as well as in cancer recurrence $^{11}$. Breast cancer stem cells (BCSCs) were initially identified as a small subpopulation of patient-derived breast cancer cells expressing $\mathrm{CD} 44^{+} / \mathrm{CD} 24^{- \text {low }}$ cell surface markers ${ }^{12}$. Tumor-derived $\mathrm{CD} 44^{+} / \mathrm{CD} 24^{- \text {low }}$ cells are able to form tumorspheres in vitro when cultured under anchorage-independent conditions in serum-free medium $^{13}$. In contrast, cells that do not express these markers do not generate tumorspheres and have lower tumorigenic potential ${ }^{14}$. BCSCs are frequently detectable in metastatic pleural effusions of breast cancer patients or early-disseminated cancer cells in the bone marrow and are resistant to chemotherapy treatment in breast cancer patients ${ }^{15,16}$. Of note, tumor cells derived from basal-like or triple-negative breast cancers are enriched in $\mathrm{CD} 44^{+}$/ CD24 ${ }^{- \text {low }}$ subpopulations ${ }^{17}$. Thus, the stem cell-like properties of BCSCs may account for the poor prognosis, high tumor recurrence, and chemotherapy resistance in TNBC patients.

The TGF $\beta$ superfamily of growth factors includes over 30 members that can be categorized under the TGF $\beta$ /Activin, bone morphogenetic protein (BMP), and distant member's main subgroups ${ }^{18}$. All members of the TGF $\beta$ superfamily exert pleiotropic effects throughout the body ${ }^{18}$. TGF $\beta$ itself, the founding member of this family plays an important role in regulating $\mathrm{BCSCs}{ }^{19-23}$. Human mammary epithelial cells undergoing an epithelial-to-mesenchymal transition in response to TGF $\beta$ and Wnt signaling have been shown to acquire stem cell-like features ${ }^{24}$. Moreover, TGF $\beta$ signaling is specifically activated in $\mathrm{CD} 44^{+} / \mathrm{CD} 24^{-/ \text {low }}$ BCSCs, leading to a mesenchymal and migratory phenotype $^{25}$. It was also shown that TGF $\beta$-induced tumorsphere formation occurs predominantly in claudin ${ }^{\text {low }}$ breast cancer (also known as basal-b subtype), as opposed to other breast cancer molecular subtypes ${ }^{26}$. Despite the accumulating evidence for the role of TGF $\beta$ in the regulation of BCSC function, the downstream targets and signaling pathways that mediate the TGF $\beta$ effects remain to be fully understood. BMP4, another member of the TGF $\beta$ superfamily plays fundamental roles in osteogenesis but also acts as a multipotent stem cell differentiating factor ${ }^{27}$. BMP4 has been shown to exert antitumor effects and to be able to re-sensitize tumors to therapy by differentiating stemlike cells in a glioma ${ }^{28}$.

The cell cycle regulator, cyclin D1, can promote stem cell expansion and inhibit differentiation of several embryonic, hematopoietic, and normal mammary progenitor cells ${ }^{29,30}$. Cyclin D1 also plays an important role during mammary gland development, as cyclin D1knockout mice fail to generate lobuloalveoli in the mammary glands during pregnancy ${ }^{31}$. Interestingly, cyclin D1 is frequently overexpressed in human breast, melanoma, prostate, lung, and oral squamous cell carcinomas $^{32-34}$. Moreover, elevated cyclin D1 expression associates with a high incidence of tumor metastasis and poor survival outcome ${ }^{35}$, and its overexpression has been shown to promote the initiation and development of breast cancer ${ }^{36}$. We have previously shown that cyclin D1 acts downstream of TGF $\beta$ to regulate breast cancer cell migration and invasion, two key features of CSC activity ${ }^{37}$. Moreover, our lab recently found that the cyclin D1 associated kinase, CDK4 can regulate cancer stemness in $\mathrm{TNBC}^{38}$. We thus, hypothesized that cyclin D1 may also regulate $B C S C$ self-renewal activity, downstream of TGF $\beta$.

In this study, we show that TGF $\beta$ promotes stemness and negatively regulates BMP4 expression in TNBC through the canonical Smad pathway and cyclin D1. We further found cyclin D1 to be highly expressed in tumorspheres compared to cells in monolayer cultures, consistent with a role in promoting stemness. Conversely, we show that BMP4 potently inhibited tumorsphere formation and reduced $\mathrm{CD} 44^{+} / \mathrm{CD} 24^{- \text {low }}$ numbers in $\mathrm{BC}$ cells. Interestingly, BMP4 also promoted differentiation of normal mammary epithelial cells, highlighting BMP4 as a potent prodifferentiation factor in both normal and breast cancer cells. Together these results define an antagonistic feedback loop and signaling network between TGF $\beta$ superfamily members, whereby TGF $\beta / \mathrm{Smad} /$ cyclin D1 signaling leads to increased cancer stem cell numbers while BMP4 oppose these effects acting as a potent differentiation factor.

\section{Methods \\ Cell lines}

All TNBC SUM cell lines were obtained from Stephen Ethier (The Medical University of South Carolina). The SCP2 cell line was kindly provided by Dr. Joan Massagué (Sloan Kettering Institute). All the cell lines were routinely tested by Diagnostic Laboratory from Comparative Medicine and Animal Resources Centre (McGill University).

\section{Cell culture}

Human breast cancer cell line SUM159PT, SUM149PT, and SUM229PE were cultured in Ham's F-12 nutrient mixture (Sigma-Aldrich) supplemented with 5\% fetal bovine serum (FBS), $5 \mu \mathrm{g} / \mathrm{ml}$ insulin, and $1 \mu \mathrm{g} / \mathrm{ml}$ hydrocortisone. Human breast cancer cell line SCP2 was 
cultured in DMEM (Sigma-Aldrich) containing 10\% FBS and $2 \mathrm{mM}$ L-glutamine. For cell transfection, please refer to Supplementary Materials and Methods.

\section{Tumorsphere formation and flow cytometry assays}

SUM159PT cells were seeded at 10,000 cells per well in 12-well low-attachment plates and grown for 5-7 days in Ham's F-12 nutrient mixture supplemented with B27, $10 \mathrm{ng} / \mathrm{ml} \mathrm{EGF}$, and $10 \mathrm{ng} / \mathrm{ml} \mathrm{bFGF}$. For detailed tumorsphere scoring and flow cytometry analysis, please refer to Supplementary Materials and Methods.

\section{Real-time PCR}

SUM159PT, SUM149PT, SUM229PE, and SCP2 cells were lysed by TRIzol reagent (Invitrogen), and the total RNA was extracted following the standard procedures. For detailed reverse transcription and PCR steps, please refer to Supplementary Materials and Methods.

\section{Western blot analysis}

Antibodies and reagents were obtained from Thermo Scientific and Santa-Cruz. For detailed information, please refer to Supplementary Materials and Methods.

\section{Luciferase assay}

The series of $5^{\prime}$-progressive deletion of the human BMP4 gene promoter fused to the luciferase gene $(3.36 \mathrm{~kb}-$ BMP4-luc, 3.17kb-BMP4-luc, 2.10kb-BMP4-luc, 1.7kbBMP4-luc, and 0.46kb-BMP4-luc) were kindly provided by Dr. Daniel Chung ${ }^{39}$. For complete steps, please refer to Supplementary Materials and Methods.

\section{D cell culture}

The morphology of mammary epithelial organoids was evaluated after $72 \mathrm{~h}$ of different treatments. For complete steps, please refer to Supplementary Materials and Methods.

\section{Immunofluorescence staining and confocal microscopy}

mammary organoids in 3D culture were fixed in 4\% PFA and permeabilized in $0.5 \%$ Triton X-100/1XPBS (PBST) before immunostaining. For complete procedures, please refer to Supplementary Materials and Methods.

\section{Gene expression profiling}

SCP2 cells were serum-starved overnight and treated with $100 \mathrm{pM}$ TGF $\beta 1$ for $24 \mathrm{~h}$ in a serum-free medium. Total RNA samples were extracted using the TRIzol reagent (Invitrogen). For complete steps, please refer to Supplementary Materials and Methods.

\section{Online data analysis}

GOBO, TCGA-BRCA datasets were used to assess BMP4 expression levels in different breast molecular subtypes. The GOBO database was further applied to analyze BMP4 expression levels according to the ER status and tumor grade. The patient numbers in each category are indicated in the corresponding figures. Kaplan-Meier plotter was used to evaluate the association between BMP4 and TGF $\beta$ mRNA level and clinical outcome represented as relapse-free survival (RFS).

\section{Statistical analyses}

All results are presented as the mean \pm SEM for at least three repeated individual experiments. The difference between groups was analyzed using Student's $t$ test, and ${ }^{*} P \leq 0.05$ was considered statistically significant.

\section{Results}

\section{TGF $\beta$ transcriptomic analysis in TNBC cells}

To start analyzing the TGF $\beta$ role on BCSC biology in TNBC, we first examined the TGF $\beta$ effects on tumorsphere formation. In this type of assay, cancer stem/progenitor cells are enriched in serum-free, nonadherent culture conditions, allowing for proper identification and quantitation of cancer stem cell numbers. We used TNBC SUM159PT cells, a TNBC cell line derived from a patient with anaplastic carcinoma ${ }^{40}$. SUM159PT cells were seeded at moderate seeding density $(10,000$ cells $)$ in the presence or the absence of TGF $\beta(100 \mathrm{pM})$, under lowattachment culture conditions, as described in "Methods". Tumorsphere forming efficiency (TFE) was determined as the number of tumorspheres divided by the number of single cells seeded, expressed as a percentage. As shown in Fig. 1a, TFE tumorsphere numbers were significantly increased in cells treated with TGF $\beta$ compared to control. This effect is mediated through the classical TGF $\beta$ receptor signaling pathway, as the addition of a specific TGF $\beta$ receptor I kinase inhibitor (T $\beta$ RIin) significantly blocked TGF $\beta$-induced tumorsphere formation (Fig. 1a). These data indicate that activation of the TGF $\beta$ signaling pathway promotes BCSC activity and self-renewal in TNBC.

To further address the molecular mechanisms by which TGF $\beta$ regulates tumor initiation in TNBC, we performed a microarray analysis, using the Illumina Human HT-12 Gene Expression BeadChip in TNBC cells treated or not with TGF $\beta$ for $24 \mathrm{~h}$. The high screen efficiency and sample correlation were reflected by the high Pearson correlation coefficient (>0.99) (Fig. 1b) and overall consistent signal intensity across biological replicates (Fig. 1c). As shown in Fig. 1d, differential gene expression (DGE) analysis using a threshold cutoff $(\mathrm{FDR}<0.05)$ revealed 290 TGF $\beta$-regulated downstream target genes, with 157 upregulated and 133 downregulated targets. A gene ontology enrichment analysis (GOEA) was then performed using EnrichR ${ }^{41,42}$ (https://amp.pharm.mssm. edu/Enrichr/) and highlighted cell migration, extracellular matrix organization, cell motility cell proliferation, and 
a
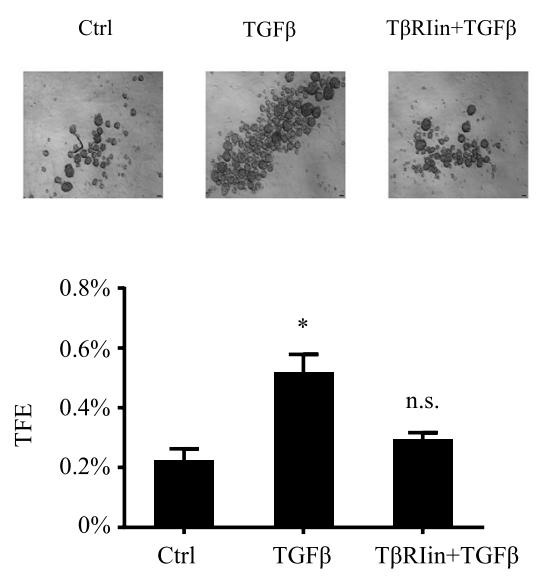

d

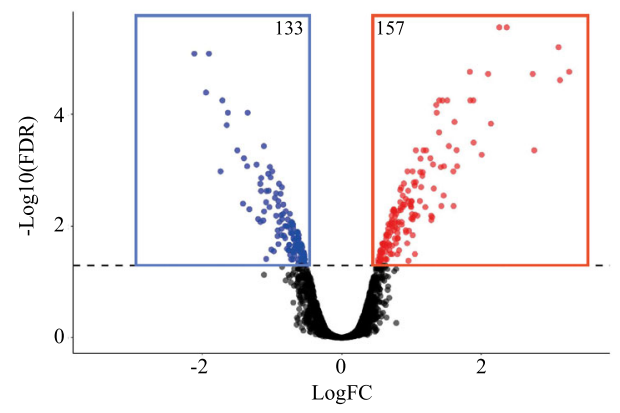

f

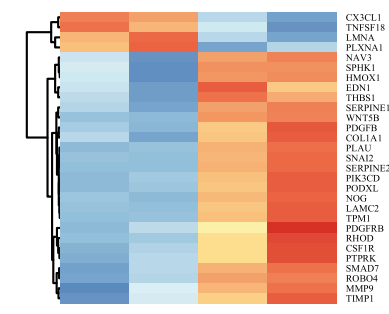

Ctrl-1 Ctrl-2 TGFß-1 TGFß-2

cell adhesion

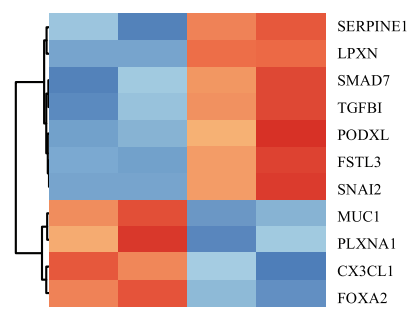

Ctrl-1 Ctrl-2 TGFß-1 TGFß-2 $\mathrm{b}$

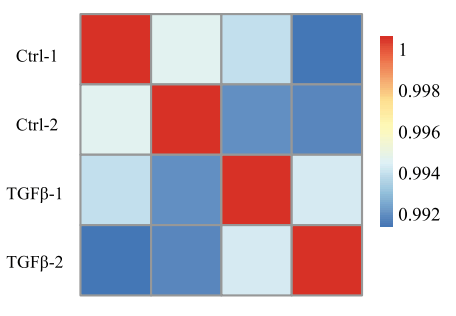

c

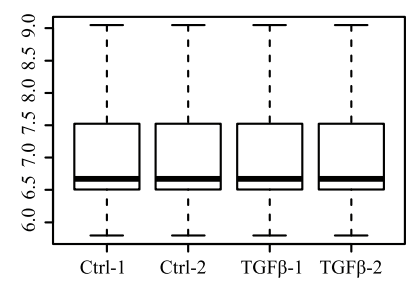

e

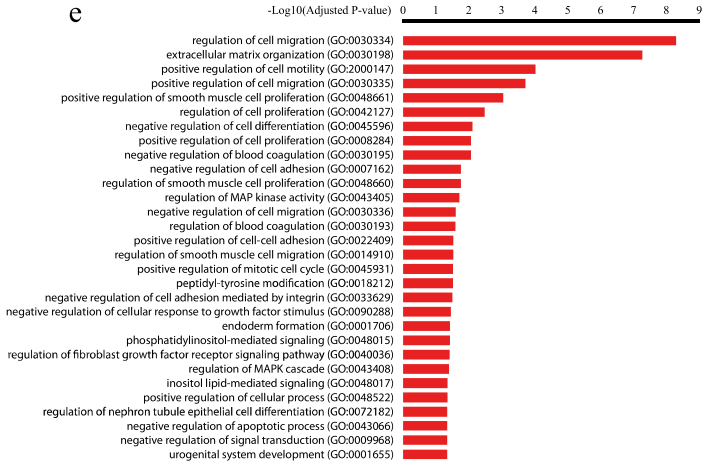

cell proliferation

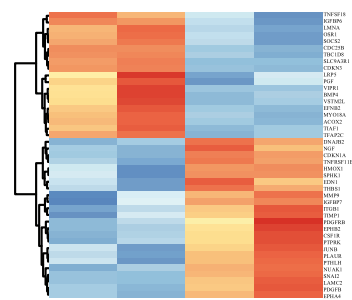

Ctrl-1 Ctrl-2 TGF $-1 \quad$ TGF $\beta-2$

endoderm formation

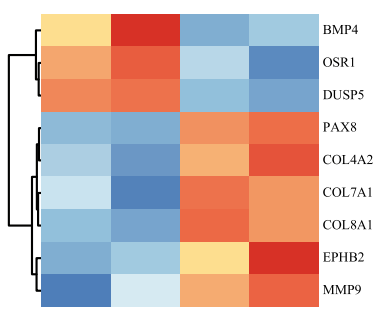

Ctrl-1 Ctrl-2 2 TGFß-1 TGFß-2

extracellular matrix organization

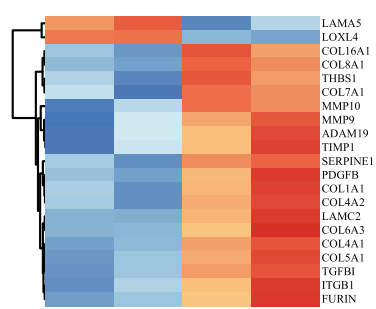

Ctrl-1 Ctrl-2 TGF $\beta$-1 TGF $\beta$-2

cell differentiation

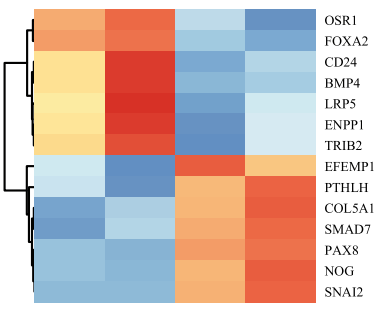

Ctrl-1 Ctrl-2 TGFß-1 TGFß-2

Fig. 1 TGF $\beta$ transcriptomic analysis in TNBC cells. a TGF $\beta$ effects on tumorsphere formation. Data are expressed as mean \pm standard error. ${ }^{*} P \leq$ 0.05 , n.s. not significant. b Pearson correlations and (c) normalized counts across all bioreplicates. $\mathbf{d}$ Volcano plot of differential expressed genes (red and blue indicate up- and downregulated genes, respectively (FDR < 0.05). e Gene ontology enrichment analysis of 290 candidate genes (FDR < 0.05) using EnrichR. $\mathbf{f}$ Heatmaps of the TGF $\beta$-regulated biological processes. 
cell differentiation as top-ranking biological functions among the 290 identified targets (Fig. 2e). Collapsing biological process (BP) terms based on functional similarity allowed for the visualization of various gene expression profiles specific to each biological function (Fig. 2f). These results are consistent with the welldescribed effects of TGF $\beta$ signaling on cell migration, motility, invasion, and proliferation in cancer cells ${ }^{18,43}$, further demonstrating the stringency and relevance of our microarray analysis. Interestingly, besides the hallmark TGF $\beta$ effects, negative regulation of cell differentiation also came out as a top-ranking biological function for the 290 identified TGF $\beta$ target genes. This is consistent with our data showing TGF $\beta$ as a potent stemness factor in TNBC (Fig. 1a) and suggested that TGF $\beta$ may exert its antidifferentiation effects through downregulation of cell differentiation genes. In particular, we found TGF $\beta$ to potently downregulate the expression of BMP4, a known cell differentiation factor, while upregulated the BMP4 antagonist Noggin (Fig. 1f). BMP4 is also a member of the TGF $\beta$ superfamily, thus suggesting the existence of a negative feedback loop between TGF $\beta$ family members to regulate the balance between cancer stemness and differentiation.

\section{TGF $\beta$ inhibits BMP4 gene expression}

As described in "Introduction", BMP4 plays a role as a differentiation factor in glioma ${ }^{28}$. We thus hypothesize that TGF $\beta$ could promote BCSC numbers and stemness through inhibition of BMP4 signaling in TNBC. Using our microarray data, we first investigated the specificity of the TGF $\beta$ effects on all BMP family member's gene expression in TNBC and found that TGF $\beta$ only regulates BMP4 expression and that no other BMP family members were significantly regulated by TGF $\beta$ (Fig. 2a). Interestingly, our transcriptomic analysis also revealed that TGF $\beta$ could significantly upregulate the expression of the BMP4 inhibitor, Noggin (NOG). To avoid the limitation of the use of a single-cell line, we then examined the TGF $\beta$ effects on BMP4 and NOG expression in a panel of human triple-negative breast cancer cell lines (SUM159PT, SUM149PT, SUM229PE, SCP2). SUM159PT is derived from an anaplastic carcinoma with mesenchymal phenotype; SUM149PT is derived from an invasive ductal carcinoma, inflammatory histotype, with Basal B phenotype; and SUM229PE is derived from a pleural effusion related to breast cancer with Basal B phenotype. The SCP2 cell line is a single-cell-derived progeny (SCP) derived from the in vivo selection of bone-specific metastatic cells from the human breast cancer TNBC cell line MDA-MB- $231^{44}$. SCP2 cells are capable of bone metastasis and pre-exist within the MDAMB-231 parent line, which was originally established as the total outgrowth of cells derived from a pleural effusion of a patient who relapsed years after removal of the primary tumor $^{45}$. We found that TGF $\beta$ could potently inhibit BMP4 expression while increasing Noggin in all cell lines tested, as early as $2 \mathrm{~h}$ following stimulation of the cells (Fig. $2 \mathrm{~b}$ ). This effect appears to be mediated at the transcriptional levels, as TGF $\beta$ could significantly repress the activity of a series of progressive BMP4 gene promoter deletion constructs fused to luciferase reporter constructs (Fig. 2c). TGF $\beta$ efficiently inhibited the activity of the shortest promoter construct (460 bp) further indicating that the TGF $\beta$ regulatory sequences are located within the proximal region of the BMP4 gene promoter, close to the $5^{\prime}$ transcription initiation start site.

TGF $\beta$ classically regulates the expression of its target genes through the canonical Smad pathway, through Smad2, 3, and $4^{18}$. To then assess whether the TGF $\beta$ effects on BMP4 and NOG expression were Smaddependent, TNBC (SUM159PT) cells were transfected with specific shRNAs targeting Smad2, 3, or 4 or a scrambled shRNA as a negative control. As shown in Fig. $2 \mathrm{~d}$, the efficacy and specificity of each shRNA were assessed by immunoblotting using specific antibodies against the Smads. Effects of the Smad knockdowns on BMP4 and Noggin expression were then assessed and quantified by qPCR and revealed that all Smad individual knockdowns significantly blocked TGF $\beta$-mediated inhibition of BMP4 expression and TGF $\beta$-induced NOG expression (Fig. 2e). Together, these results that TGF $\beta /$ Smad signaling strongly antagonizes BMP4 signaling through multiple pathways, including direct repression of BMP4 gene expression with concomitant up-regulation of the BMP4 inhibitor, Noggin.

\section{Cyclin D1 is a downstream mediator of TGF $\beta$-induced BMP4 downregulation}

We previously identified cyclin D1 as an important player downstream of TGF $\beta$ signaling in TNBC and showed that TGF $\beta$ itself could upregulate cyclin D1 expression ${ }^{37}$. Besides acting as a cell cycle regulator, cyclin D1 was also shown to act as an important protooncogene. In fact, cyclin D1 is frequently deregulated in multiple tumor types and overexpressed through copy number variation in over $50 \%$ of breast cancer patients ${ }^{46}$. To then address whether TGF $\beta$-mediated regulation of BMP4 and stemness also involves cyclin D1 in TNBC, we knockdown cyclin D1 expression by means of RNA interference (Fig. 3a). Interestingly, as shown in Fig. 3b, the TGF $\beta$-mediated inhibition of BMP4 gene expression was strongly impaired in the absence or reduced levels of cyclin D1. Similarly, when cyclin D1 was knockdown, the TGF $\beta$ inhibitory effects on BMP4 gene promoter activity were significantly reversed (Fig. 3c), indicating that TGF $\beta$-mediated regulation of BMP4 requires cyclin D1. Having shown that TGF $\beta$ inhibits BMP4 while promotes stemness, we next assessed the role and contribution of cyclin D1 in controlling cancer stem cell numbers. The 
a

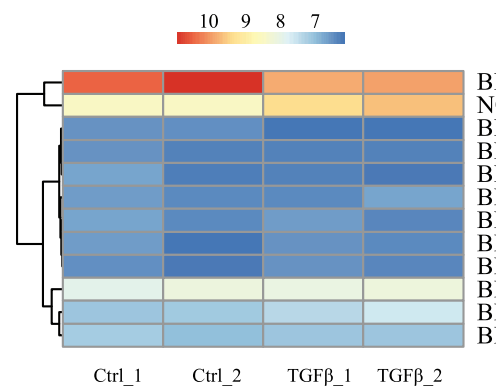

adj.P-Value

0.0164

0.0164

0.389

0.945
0.859

0.859
0.976

0.976

0.971

0.945

0.379 0.982

b
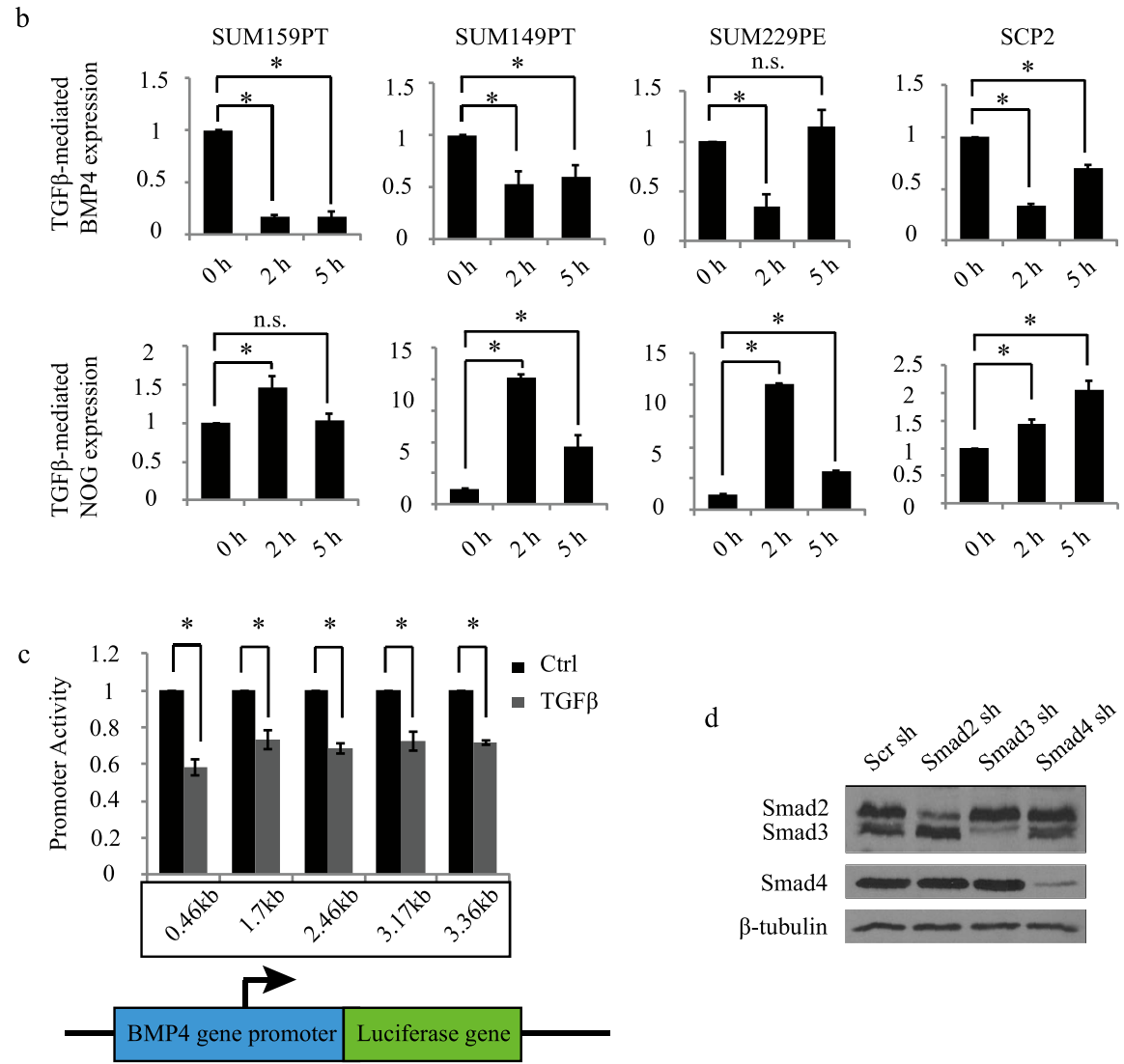

d

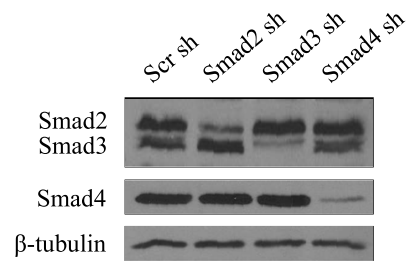

e
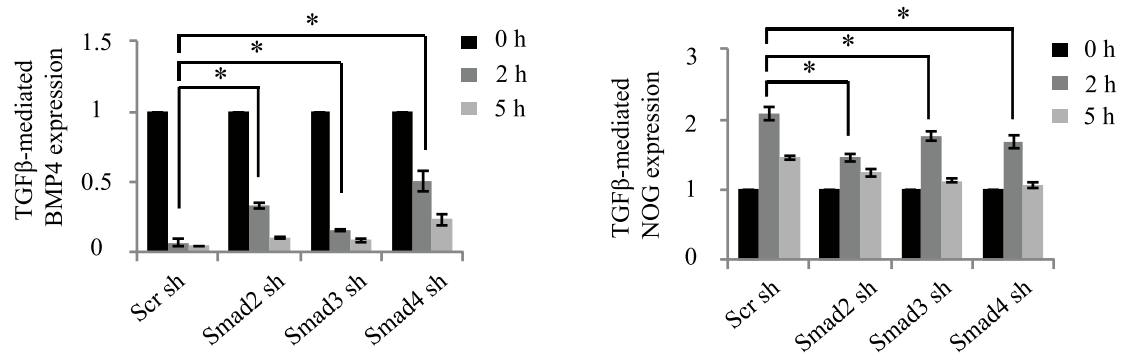

Fig. 2 BMP4 and NOG are inversely regulated by TGF $\beta$. a Heatmap representing the TGF $\beta$ effects on BMP family members and NOG expression with log fold change and adjusted $P$ value. $\mathbf{b}$ QPCR analysis of BMP4 and NOG in various TNBC cell lines. Data represent means \pm SEM of triplicate experiments. ${ }^{*} \leq \leq 0.05$; n.s. not significant. $\mathbf{c}$ TGF $\beta$ effects on progressive deletion constructs of the BMP4 gene promoter fused to luciferase. Data were normalized to the control group, and graphs are means \pm SEM from triplicate data. ${ }^{*} P \leq 0.05$; n.s. not significant. $\mathbf{d}$ Immunoblots of the Smad knockdown efficiencies. e Smad knockdown effects on TGF $\beta$-mediated BMP4 and NOG expression. 
a

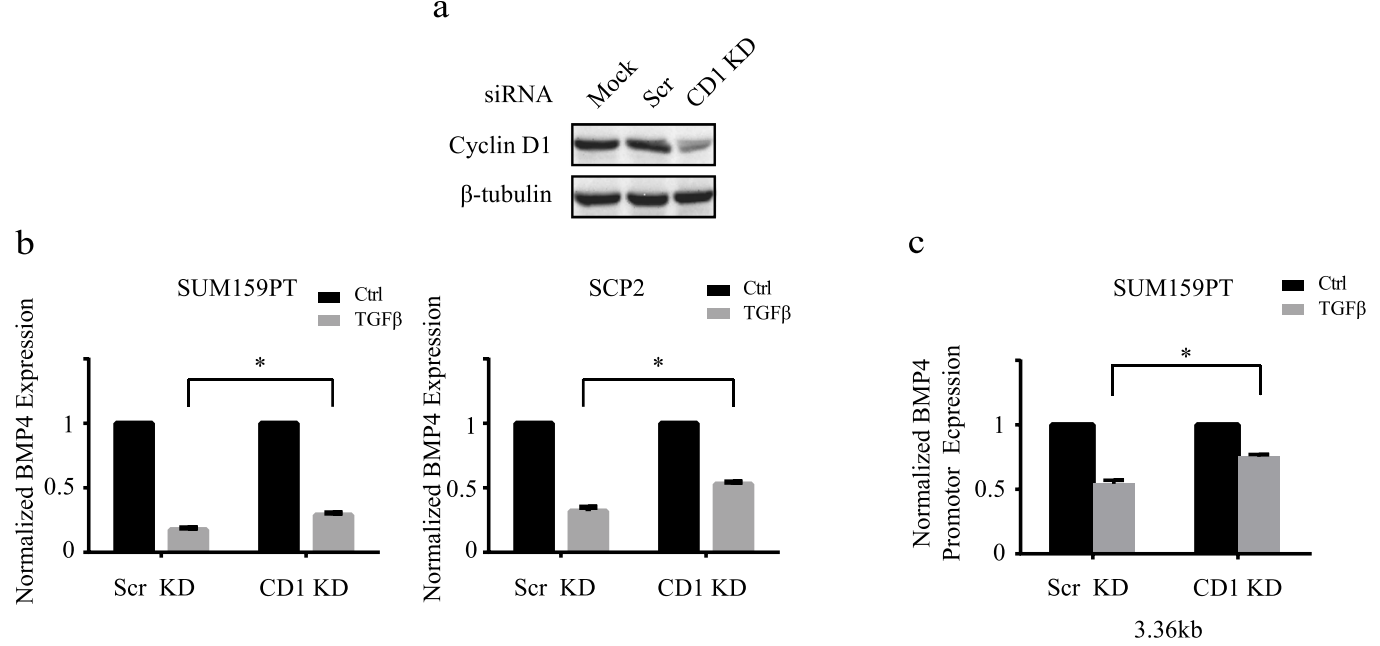

b

d
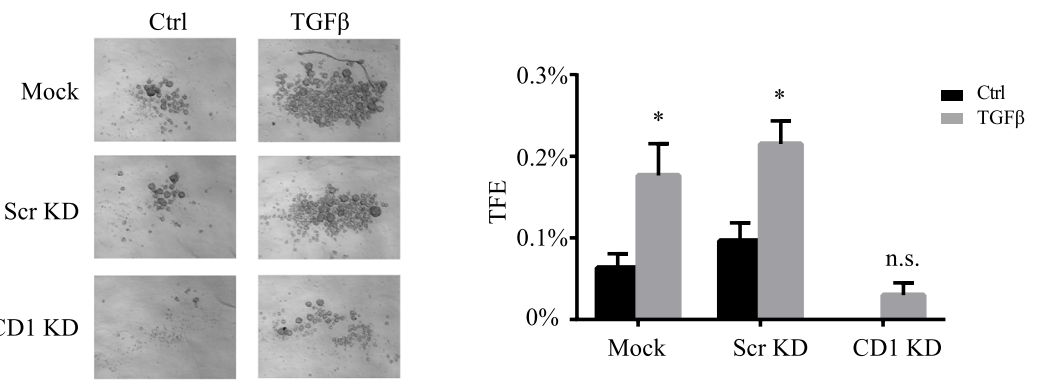

e

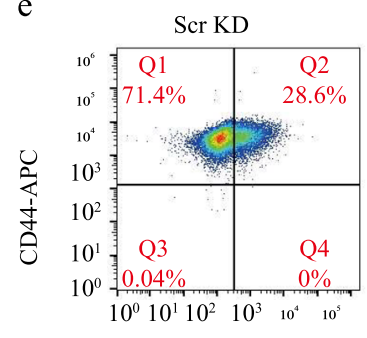

$\mathrm{CD} 1 \mathrm{KD}$

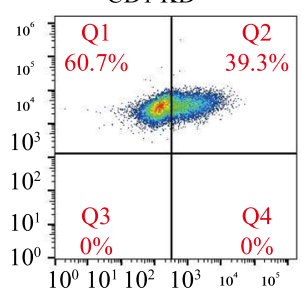

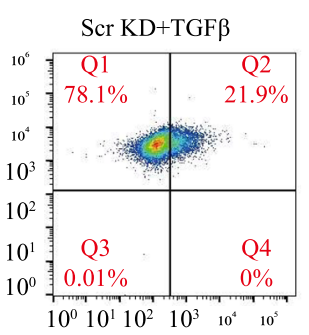

$\mathrm{CD} 1 \mathrm{KD}+\mathrm{TGF} \beta$

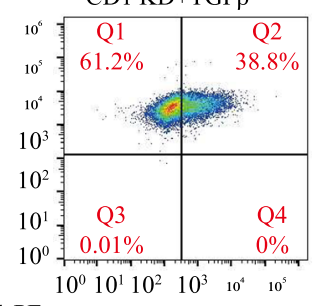

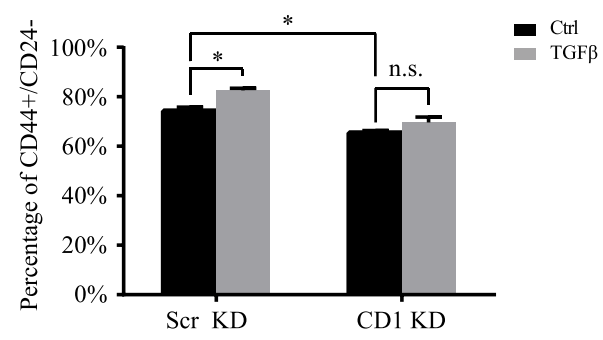

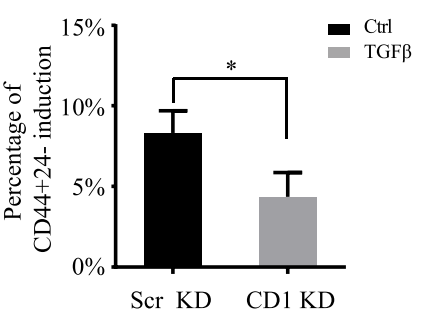

Fig. 3 Cyclin D1 is required for TGF $\beta$ inhibition of BMP4. a Immunoblot analysis to assess cyclin D1 knockdown efficiency. b Cyclin D1 knockdown effects on TGF $\beta$-mediated BMP4 expression. c Cyclin D1 knockdown effects on TGF $\beta$-mediated BMP4 gene promoter inhibition. $\mathbf{d}$, e Cyclin D1 knockdown effects on TGF $\beta$-mediated tumorsphere formation (d) and TGF $\beta$-induced CD $44^{\text {high }} / \mathrm{CD} 24^{- \text {llow }}$ cell numbers (e). Data represent means \pm SEM of triplicate experiments. ${ }^{*} P \leq 0.05$; n.s. not significant.

two main CSC populations present in breast cancer are of epithelial stem-like (ADLH+) and mesenchymal stem celllike phenotype $\left(\mathrm{CD} 44^{\text {high }} / \mathrm{CD} 24^{\text {low }}\right)$ origins. Importantly, while ADLH + CSCs are enriched in the HER2+ subtype, they only represent a minority CSC population in TNBC. Indeed, the most prominent CSC population in TNBCs 
are the mesenchymal CD $44^{\text {high }} / \mathrm{CD} 24^{\text {low }}$ cancer stem cells, which are known to drive the aggressive nature of TNBC tumors. Thus, to start to investigate and characterize the TGF $\beta / B M P 4$ signaling cross-talk/network and stemness/ pro-differentiation effects in TNBC, we examined these growth factor's effects on tumorsphere formation (to reflect global CSC numbers) and specifically analyzed their effects on the predominant $\mathrm{CD} 44^{\text {high }} / \mathrm{CD} 24^{\text {low }}$ CSC subpopulation in those tumors. As shown in Fig. 3d, TGF $\beta$ strongly increased tumorsphere numbers in TNBC but these effects were significantly reduced in the absence of cyclin D1. As indicated above, a major CSC group in $\mathrm{TNBC}$ is represented by the $\mathrm{CD} 44^{\text {high }} / \mathrm{CD} 24^{-/ \text {low }}$ cancer stem cell population. $\mathrm{CD} 44^{\text {high }} / \mathrm{CD} 24^{- \text {low }}$ breast cancer cells display greater stem cell-like features and tumorigenic capacity compared to CD $44^{-}$and $\mathrm{CD} 24^{+}$cells $^{47}$. We thus examined the TGF $\beta$ and cyclin D1 knockdown effects on this CSC population using flow cytometry, as we previously described $^{23,38}$. As shown in Fig. 3e, while TGF $\beta$ significantly increased the CD $44^{\text {high }} / \mathrm{CD} 24^{-/ \text {low }}$ cell numbers, this effect was blocked in the absence of cyclin D1. The flow cytometry results are in line with our tumorsphere assay data and further indicate the requirement of cyclin D1 for TGF $\beta$ to promote stemness in breast cancer.

\section{BMP4 acts as a differentiation factor and inhibits TGF $\beta$-induced stemness}

We next sought to further characterize the BMP4 pro-differentiation role in TNBC and investigate the antagonistic effects played by TGF $\beta / B M P 4$ in the regulation of stemness in TNBC. For this, SUM159PT cells were treated or not with different concentrations of BMP4 for 7 days, as indicated in Fig. 4a before being assessed for tumorsphere efficiency and cell numbers (after tumorspheres were dissociated into single tumor cells). As shown in Fig. 4a, we found increasing BMP4 concentrations to concomitantly decrease tumorsphere efficiency and cell numbers for up to $50 \%$ and $75 \%$, respectively, when using the highest BMP4 dose $(100 \mathrm{ng} / \mathrm{ml})$. Conversely, as shown in Fig. $4 \mathrm{~b}$, TGF $\beta$ could increase both tumorsphere efficiency and tumor cell numbers but these effects were antagonized and reversed when both TGF $\beta$ and BMP4 were added, suggesting that restoring BMP4 signaling and cell differentiation could block TGF $\beta$-mediated stemness. Similarly, when assessing these growth factor effects on the $\mathrm{CD} 44^{+} / \mathrm{CD} 24^{-/ \text {low }}$ cancer stem cell population, we found that BMP4 acted as a differentiation factor, able to decrease both basal and TGF $\beta$-induced BCSC numbers (Fig. 4c). Altogether, these results indicate that the two family members, BMP4 and TGF $\beta$, antagonize each other effect in the regulation of cancer stemness and highlight BMP4 as a potent pro-differentiation factor in TNBC.

\section{BMP4 differentiates mammary epithelial cells into an acinar structure in $3 \mathrm{D}$ cell culture}

We next evaluated whether BMP4 could act as differentiation and a polarity morphogenic factor in normal mammary epithelial cells to induce the formation of mammary acinar structures. For this, we performed ex vivo acini morphogenesis assays as described previously $^{48}$ using primary mammary epithelial cells isolated from female virgin mice. As indicated in Fig. 5a, BMP4 stimulation strongly induced the formation of organized mammary acini with well-established apical/ basal polarity as indicated by the apical localization of ZO-1 and basal/lateral localization of E-cadherin. On the other hand, control and TGF $\beta$ stimulated cells did not show any organized acini-like structures. Interestingly, stimulation of the cells with TGF $\beta$, in addition to BMP4, strongly antagonized the BMP4 effects on acinar morphogenesis. Having shown the BMP4/TGF $\beta$ effects on acinar structures, lumen formation, and polarity, we then quantified the numbers of acini observed in the different conditions. As shown in Fig. 5b, the acinar formation efficiency (percentage of acini/colonies) was significantly increased by BMP4 treatment and this effect was antagonized in the presence of TGF $\beta$. Together, these results highlight BMP4 as a potent differentiation factor in normal mammary epithelial cells, able to promote the formation of well-organized 3D acinar structures and show that TGF $\beta$ can efficiently antagonize these BMP4 differentiation effects.

\section{BMP4 expression correlates with least aggressive breast cancer subtypes and is associated with beneficial clinical features}

Having shown that BMP4 acts as a differentiation factor in both normal and cancer cells, able to decrease BCSC numbers, we then investigated its potential as a predictive molecular marker for breast cancer patients. For this, we performed bioinformatics analysis using $\mathrm{GOBO}^{49}$ and TCGA-BRCA $^{50}$ online databases to identify any correlation between BMP4 gene expression and breast cancer clinical features. We first analyzed BMP4 mRNA expression levels across different breast cancer molecular subtypes. As shown in Fig. 6a, analysis of the GOBO database revealed BMP4 expression levels to be the highest in the least aggressive luminal A subtype, while being the lowest in the most aggressive, invasive basal subtype. Analysis of the TCGA-BRCA dataset revealed a similar pattern (Fig. $6 \mathrm{~b})$, indicating that the lowest BMP4 expression levels correlate with the most aggressive breast cancer subtypes. Moreover, as shown in Fig. 6c, BMP4 expression was significantly higher in ER+ tumors compared to ERtumors, consistent with the fact that cancer stem cell markers are usually associated with ER status and predictive of a poor survival outcome in ER- patients $^{51}$. 


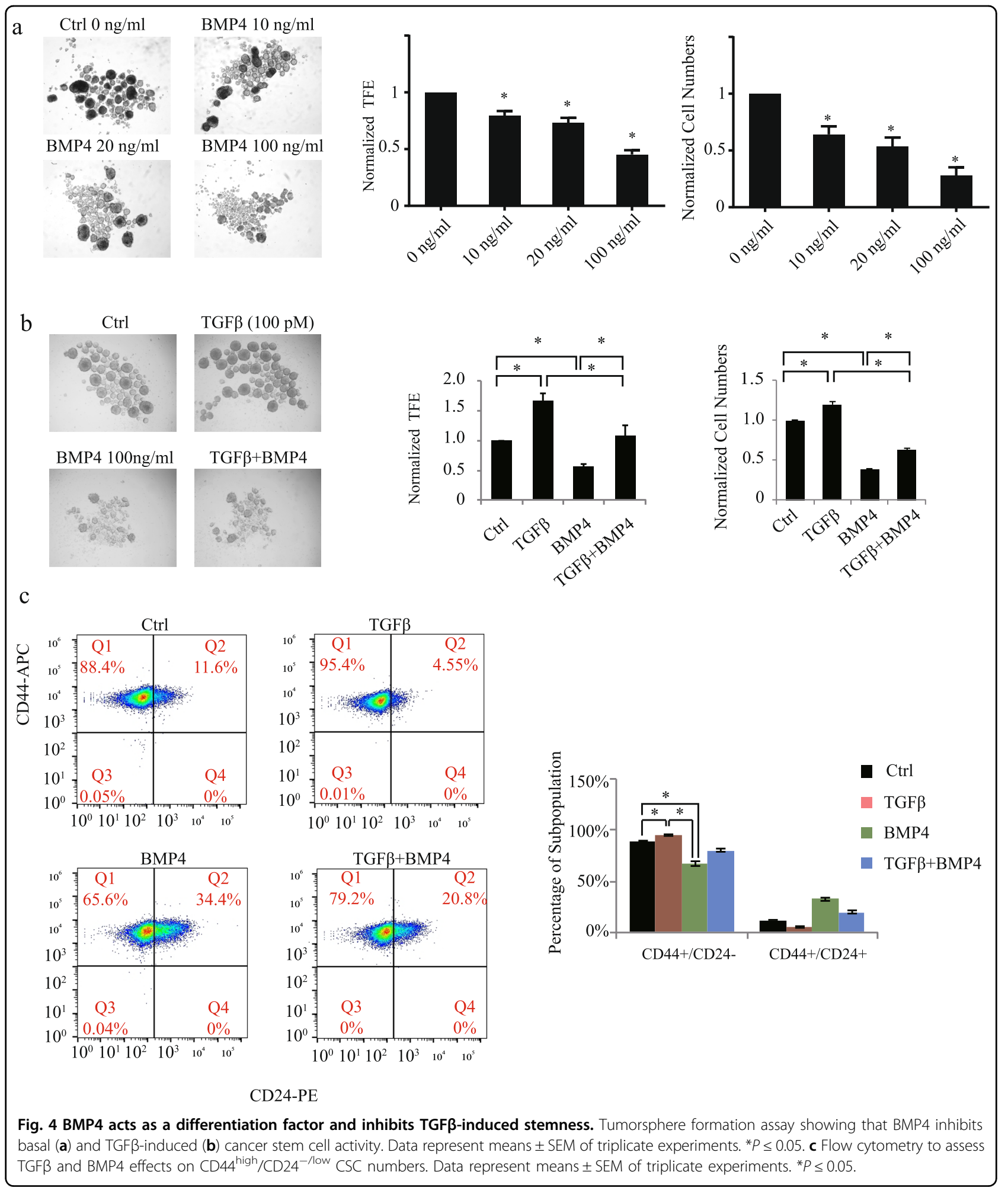

Tumor grade represents a clear indicator of the differentiation stage and growth rate of tumor cells. Whereas grade 1 tumors are well-differentiated with a slow growth index, grade 2 tumors are moderately differentiated with an intermediate growth index, while grade 3 tumors exhibit high CSC content and very poor differentiation states with features favoring rapid growth ${ }^{52,53}$. Interestingly, as shown in Fig. 6d, BMP4 expression levels 


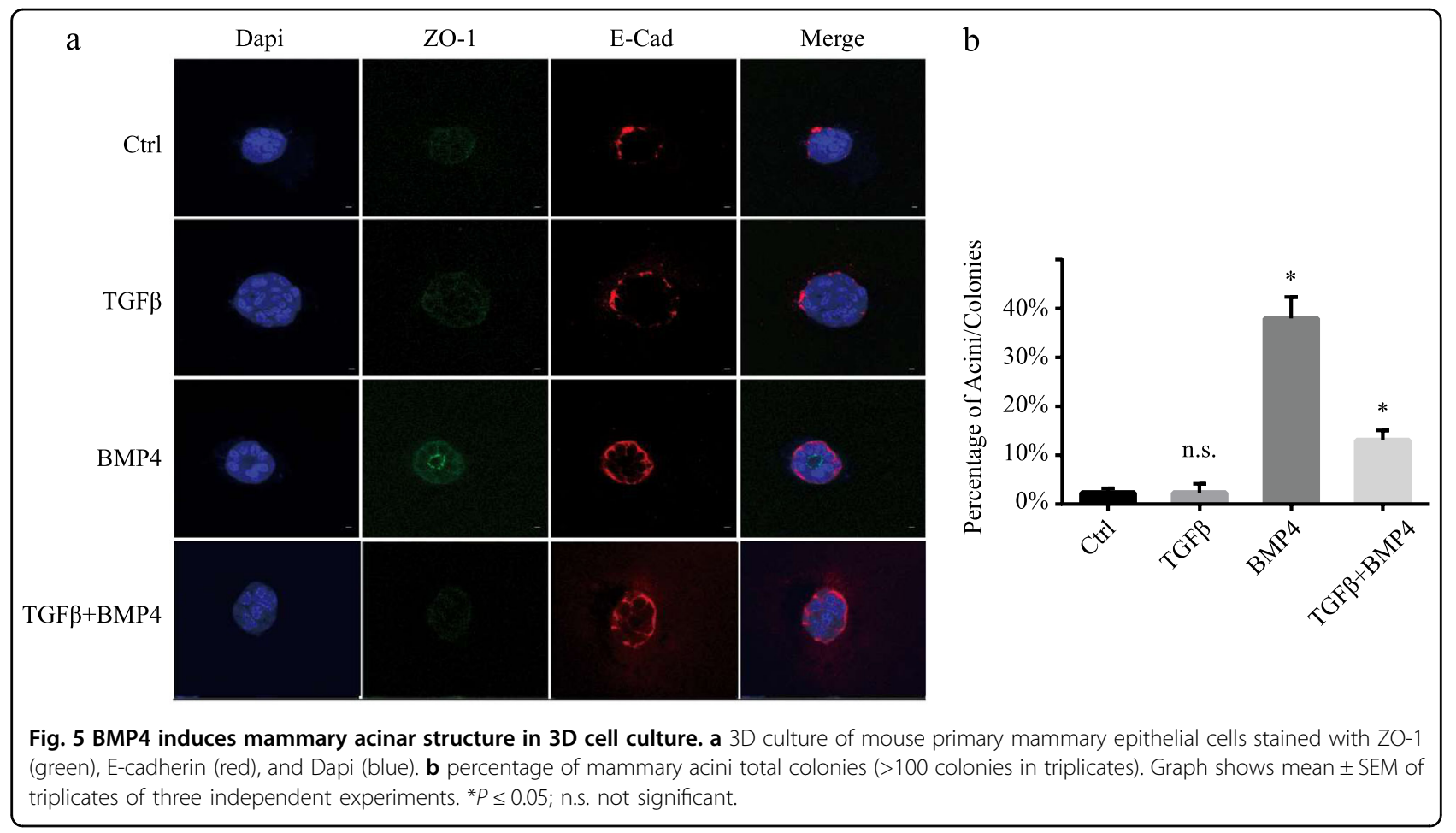

inversely correlated with the increasing tumor grade. To further explore the relationship between BMP4 gene expression and patient clinical outcomes, we also performed Kaplan-Meier analysis ${ }^{54}$, using a large cohort of 3557 breast cancer patients. As shown in Fig. 6e, low BMP4 expression significantly correlated with poor relapse-free survival, while TGF $\beta$ expression showed the opposite trend (Fig. 6f). The opposing clinical outcomes for BMP4 and TGF $\beta$ are consistent with our findings, whereby expression of pro-differentiation factors, such as BMP4 efficiently reduces CSC stemness and correlates with less aggressive tumors and much improved patient survival outcomes, opposite to what observed with stemness factors, such as TGF $\beta$.

\section{Discussion}

Cancer stem cells are emerging as an attractive clinical therapeutic target for many types of cancer. In breast cancer, many reports have indicated that BCSCs are associated with resistance to conventional therapies such as chemotherapy or radiotherapy, and have the ability to regrow tumors resulting in later relapse of breast cancer patients ${ }^{55,56}$. In particular, the TNBC molecular subtype is highly enriched in cancer stem cells and exhibits a high incidence of distant relapse disease following chemotherapy treatment ${ }^{3}$. To date, there is no efficient targeted therapy for this type of cancer, thus defining a clear unmet medical need for these TNBC patients. As such, a better understanding of the molecular mechanisms underlying the regulation of stem-like properties of BCSCs and identification of the upstream growth factor signaling pathways that control these events will be instrumental for the development of novel clinical therapeutic strategies against TNBC.

Components of the TGF $\beta$ signaling cascade, including its receptors and downstream target genes, are highly expressed in ER- breast tumors, enriched in $\mathrm{CD} 44^{+} /$ $\mathrm{CD} 24^{- \text {low }}$ cancer stem cells, and their expression is associated with a significant shortening of distant metastasis-free survival outcome ${ }^{23}$. In this study, we found that TGF $\beta$ significantly promotes the self-renewal activity of cancer stem cells in TNBC and that blocking TGF $\beta$ type I receptor kinase activity with a specific smallmolecule inhibitor efficiently prevented these effects. These results indicate that TGF $\beta$ signaling plays a prominent role in perpetuating stemness in breast cancer, and are in line with the previously established promigratory/invasive/metastatic role exerted by this growth factor in advanced, aggressive TNBC tumors ${ }^{37,57-60}$. Thus, targeting specific components of the TGF $\beta$ signaling pathways represents an interesting option for efficiently targeting cancer stem cells and for treating TNBC patients with recurrent locoregional or metastatic tumors.

Cyclin D1 is one of the critical regulators of embryonic, hematopoietic, and mammary stem cells ${ }^{29,61-63}$. Deregulation of cyclin D1 expression has been observed in many types of human cancers ${ }^{64}$. A correlation between overexpression of cyclin D1 and poor clinical outcomes 


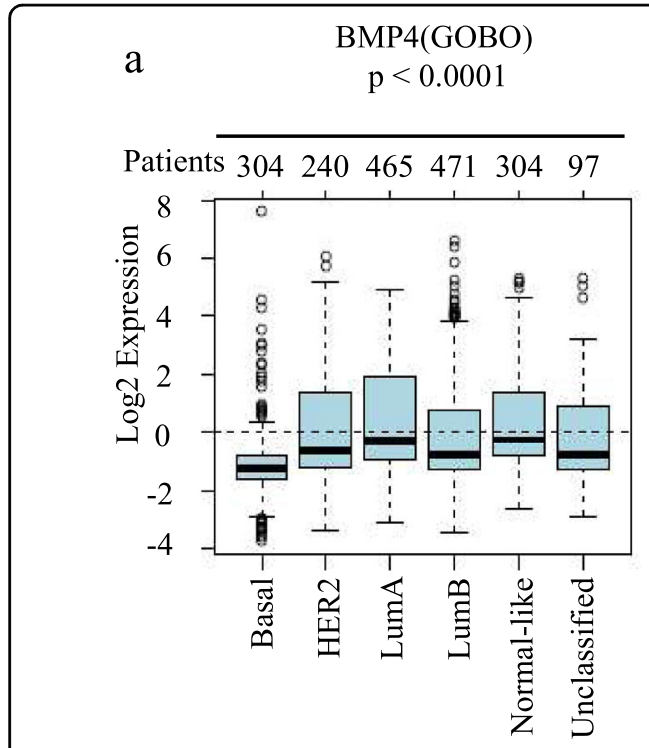

c

BMP4 expression and ER status

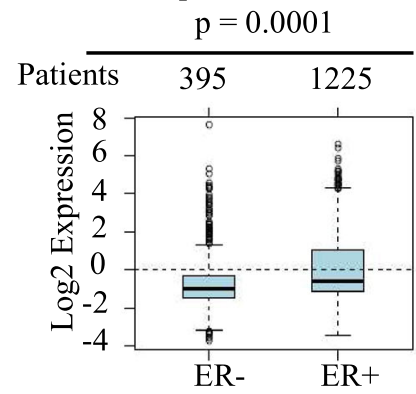

e

BMP4

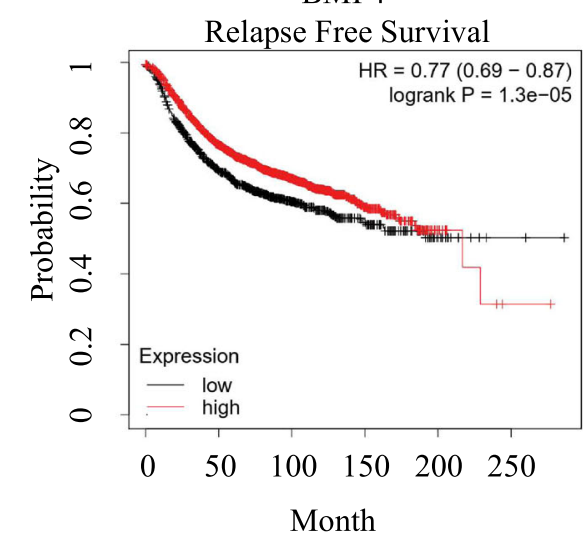

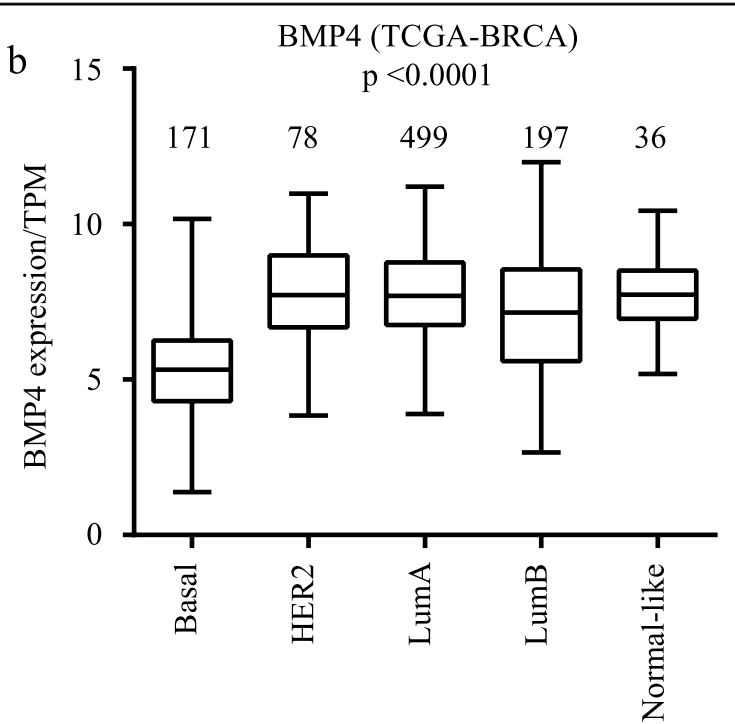

d BMP4 expression and grade status

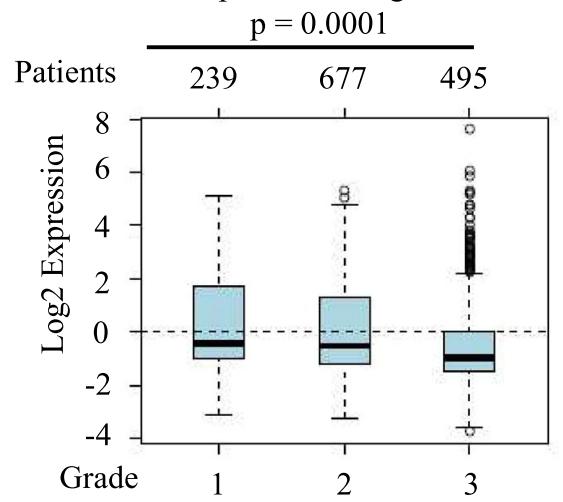

f

TGF $\beta$

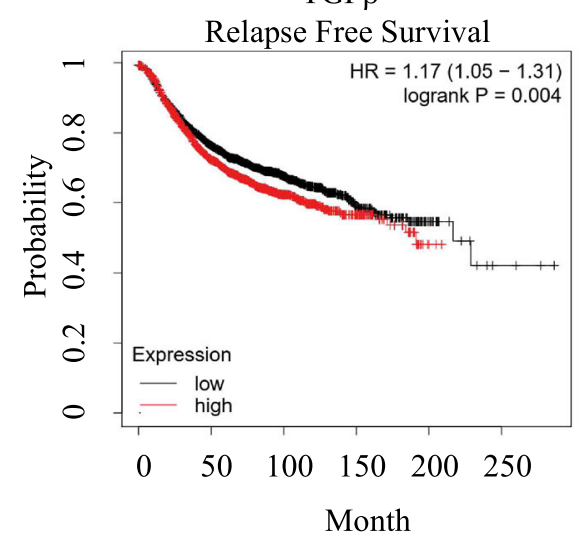

Fig. 6 BMP4 expression correlates with least aggressive breast cancer subtypes and is associated with beneficial clinical features.

$\mathbf{a}$, b Boxplot of BMP4 expression across different breast cancer subtypes using GOBO (a) and TCGA-BRCA (b) datasets. The number of patients for each subtype is indicated. $\mathbf{c}$, d Boxplot of BMP4 expression in breast cancer patients classified by ER status (c) and tumor grades (d). e Kaplan-Meier survival analysis for RFS by splitting patients into low and high BMP4 expression groups. $\mathbf{f}$ Kaplan-Meier relapse-free survival analysis for TGF $\beta$. 
has been also been established ${ }^{65,66}$. We previously showed that cyclin D1 cooperates with p21 to regulate TGF $\beta$-mediated breast cancer cell migration and tumor local invasion through transcriptional regulation of Smad activity in a CDK4-independent manner ${ }^{37}$. We showed here that cyclin D1 is required for TGF $\beta$-mediated stem cell activity and self-renewal in TNBC cells. Interestingly, cyclin D1 was previously found to be required for the selfrenewal of mammary stem and progenitor cells that are targets of MMTV-ErbB2 tumorigenesis ${ }^{63}$. Thus, cyclin D1 may play a broader role in regulating the activity and selfrenewal properties of various progenitor cells in various breast tumors of different molecular subtypes. Our results also strengthen previous findings highlighting cyclin D1 as an important therapeutic target in cancer ${ }^{67}$.

Within the TGF $\beta$ superfamily, the TGF $\beta$ s maintain embryonic stem cell pluripotency and self-renewal capacity by modulating gene expression of pluripotent transcriptional factors (Nanog, Oct4, Sox2), while other members, such as the BMPs, act as embryonic stem cell differentiation factors ${ }^{68,69}$. In cancer, BMP4 was shown to promote CSC differentiation, leading to diminished tumorigenic capacity and increased sensitivity to chemotherapy drugs in hepatocellular carcinoma and colorectal cancer models ${ }^{70,71}$. However, BMP4 role and contribution to tumorigenesis remain controversial as some studies also suggested that BMP4 could exert a dual role and exhibit pro-migratory and pro-invasive functions in breast cancer ${ }^{72,73}$. We show here that BMP4 acts as a potent differentiation factor and prevents cancer stemness by inhibiting tumorsphere formation and reducing $\mathrm{CD} 44^{+} / \mathrm{CD} 24^{-}$CSC numbers in TNBC. Consistent with this, we found that BMP4 expression is lower in basal-like, ER - and high-grade breast tumors, all of which being enriched in BCSC and having the worst prognostic features. Considering the difference in CSC content observed between the different molecular breast cancer subtypes ${ }^{74}$, this suggests that BMP4-targeting therapies should be primarily developed and be more efficient for CSC enriched/driven tumors, such as basal-like or TNBC. Finally, using normal mammary epithelial 3D cell culture assay, we also showed that BMP4 acts as a differentiation factor in normal cells and can induce the formation of 3D acinar structures, further broadening its role as a differentiation factor in normal and cancer cells. These effects of BMP4 on mammary acini morphogenesis, suppression of breast cancer stemness, and association of its expression with differentiated low-grade breast cancer subtypes are reminiscent of another key mammary differentiation factor, the prolactin hormone. Indeed, prolactin and its receptor were also shown to mediate mammary acini morphogenesis ${ }^{48}$ and their expression was also observed to correlate with less aggressive breast cancer phenotypes, including low-grade tumors and luminal breast cancer

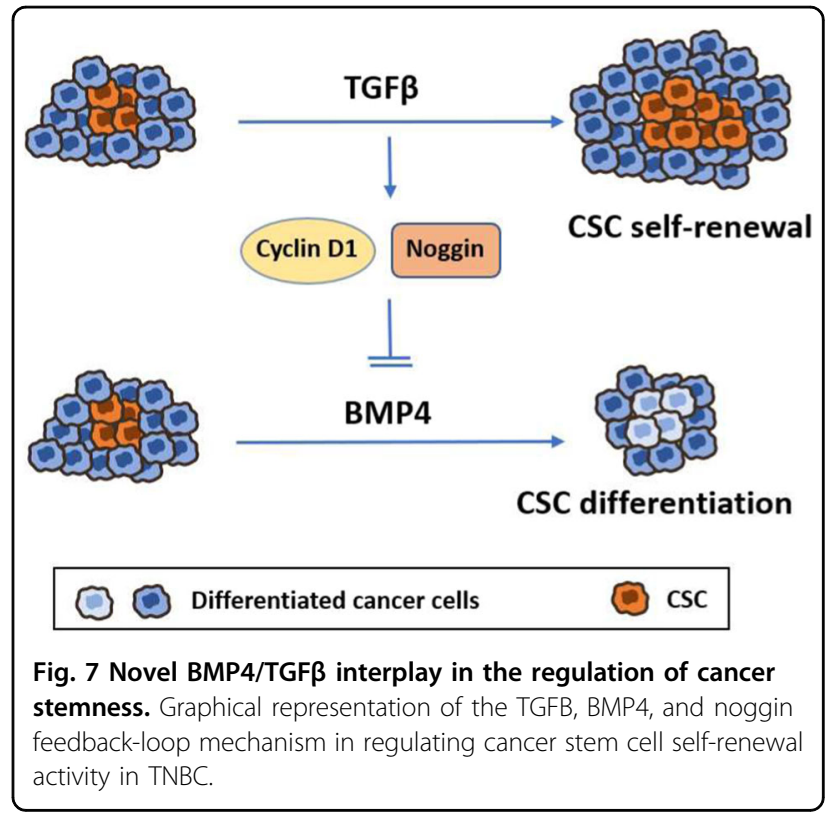

subtype $^{75,76}$. Interestingly, we also previously found antagonistic cross-talk between TGF $\beta$ and prolactin in breast cancer ${ }^{77}$. Altogether, these findings provide evidence supporting the notion that mammary differentiation factors may provide opportunities for the development of much needed cancer stem cells targeted therapeutics.

In summary, we defined a novel interplay between TGF $\beta$ family members in the regulation of cancer stemness. As represented in Fig. 7, we showed that TGF $\beta$ could act in a powerful feedback loop to repress BMP4 expression while inducing expression of the BMP4 inhibitor, Noggin, and as a result promote CSC self-renewal in TNBC. We further found TGF $\beta$ and BMP4 to antagonize each other effect on cancer stemness in high-grade, invasive basal-like tumors, and show that their relative expression (high TGF $\beta /$ low BMP4 levels) correlated with poor prognosis and survival outcomes. This study opens up new avenues for developing anti-CSC therapies targeting TGF $\beta$ signaling (i.e., small kinase inhibitors) and/or using BMP4 mimics that could prove efficient as novel targeted therapies for TNBC patients.

\section{Acknowledgements}

Canadian Institutes for Health Research (CIHR) grant provided the funding for this study (to J.J.L.). We thank Drs. Stephen Ethier and Joan Massagué for kindly providing the SUM159PT and SCP2 cell lines, respectively, and Dr. Daniel Chung for the human BMP4 gene promoter luciferase constructs.

\section{Author contributions}

G.Y., M.D., and J.J.L. were involved in designing all experiments. G.Y., M.D., and C.J.Z. performed the experiments. G.Y. and M.D. conducted microarray data analysis and analyzed the online database. A.M. performed 3D cell culture. S.P., N.W., J.B., and S.A. assisted in designing experiments and editing the paper. J.J.L. supervised the project and contributed to paper writing. All authors read and approved the final paper. 


\section{Funding}

This study was funded by a grant from the Canadian Institutes for Health Research (CIHR to J.J.L.).

\section{Data availability}

All data generated or analyzed during this study are included in this published article and its Supplementary Information files.

\section{Conflict of interest}

The authors declare no competing interests.

\section{Publisher's note}

Springer Nature remains neutral with regard to jurisdictional claims in published maps and institutional affiliations.

Supplementary information The online version contains supplementary material available at https://doi.org/10.1038/s41389-021-00310-5.

Received: 1 November 2020 Revised: 8 February 2021 Accepted: 10 February 2021

Published online: 01 March 2021

\section{References}

1. Lehmann, B. D. et al. Identification of human triple-negative breast cancer subtypes and preclinical models for selection of targeted therapies. J. Clin. Investig. 121, 2750-2767 (2011).

2. Haffty, B. G. et al. Locoregional relapse and distant metastasis in conservatively managed triple negative early-stage breast cancer. J. Clin. Oncol. 24, 5652-5657 (2006)

3. Dent, R. et al. Triple-negative breast cancer: clinical features and patterns of recurrence. Clin. Cancer Res. 13, 4429-4434 (2007).

4. Rody, A. et al. A clinically relevant gene signature in triple negative and basallike breast cancer. Breast Cancer Res. 13, R97 (2011).

5. Loi, S. et al. Prognostic and predictive value of tumor-infiltrating lymphocytes in a phase III randomized adjuvant breast cancer trial in node-positive breast cancer comparing the addition of docetaxel to doxorubicin with doxorubicinbased chemotherapy: BIG 02-98. J. Clin. Oncol. 31, 860-867 (2013).

6. Denkert, C. et al. Tumor-associated lymphocytes as an independent predictor of response to neoadjuvant chemotherapy in breast cancer. J. Clin. Oncol. 28, 105-113 (2010).

7. He, J. et al. Prognostic value of androgen receptor expression in operable triple-negative breast cancer: a retrospective analysis based on a tissue microarray. Med. Oncol. 29, 406-410 (2012).

8. Tang, D., Xu, S., Zhang, Q. \& Zhao, W. The expression and clinical significance of the androgen receptor and E-cadherin in triple-negative breast cancer. Med. Oncol. 29, 526-533 (2012).

9. Prager, B. C., Xie, Q., Bao, S. \& Rich, J. N. Cancer stem cells: the architects of the tumor ecosystem. Cell Stem Cell 24, 41-53 (2019).

10. Ayob, A. Z. \& Ramasamy, T. S. Cancer stem cells as key drivers of tumour progression. J. Biomed. Sci. 25, 20 (2018).

11. Clarke, M. F. Clinical and therapeutic implications of cancer stem cells. N. Engl. J. Med. 380, 2237-2245 (2019).

12. Al-Hajj, M., Wicha, M. S., Benito-Hernandez, A., Morrison, S. J. \& Clarke, M. F. Prospective identification of tumorigenic breast cancer cells. Proc. Natl Acad. Sci. USA 100, 3983-3988 (2003).

13. Dontu, G. et al. In vitro propagation and transcriptional profiling of human mammary stem/progenitor cells. Genes Dev. 17, 1253-1270 (2003).

14. Hinohara, K. et al. ErbB receptor tyrosine kinase/NF-kappaB signaling controls mammosphere formation in human breast cancer. Proc. Natl Acad. Sci. USA 109, 6584-6589 (2012).

15. Li, X. et al. Intrinsic resistance of tumorigenic breast cancer cells to chemotherapy. J. Natl Cancer Inst. 100, 672-679 (2008).

16. Balic, M. et al. Most early disseminated cancer cells detected in bone marrow of breast cancer patients have a putative breast cancer stem cell phenotype. Clin. Cancer Res. 12, 5615-5621 (2006).

17. Idowu, M. O. et al. CD44+/CD24-/low cancer stem/progenitor cells are more abundant in triple-negative invasive breast carcinoma phenotype and are associated with poor outcome. Hum. Pathol. 43, 364-373 (2012).
18. Lebrun, J. J. The dual role of TGFbeta in human cancer: from tumor suppression to cancer metastasis. ISRN Mol. Biol. 2012, 381428 (2012).

19. Nishimura, E. K. et al. Key roles for transforming growth factor beta in melanocyte stem cell maintenance. Cell Stem Cell 6, 130-140 (2010).

20. Ikushima, $\mathrm{H}$. et al. Autocrine TGF-beta signaling maintains tumorigenicity of glioma-initiating cells through Sry-related HMG-box factors. Cell Stem Cell 5, 504-514 (2009).

21. Humbert, L., Neel, J. C. \& Lebrun, J. J. Targeting TGF-beta signaling in human cancer therapy. Trends Cell Mol. Biol. 5, 69-107 (2010).

22. Nakano, M. et al. Dedifferentiation process driven by TGF-beta signaling enhances stem cell properties in human colorectal cancer. Oncogene $\mathbf{3 8}$, 780-793 (2019).

23. Tian, J. et al. Cyclooxygenase-2 regulates TGFbeta-induced cancer stemness in triple-negative breast cancer. Sci. Rep. 7, 40258 (2017).

24. Scheel, $C$. et al. Paracrine and autocrine signals induce and maintain mesenchymal and stem cell states in the breast. Cell 145, 926-940 (2011).

25. Cruz-Lozano, M. et al. Hydroxytyrosol inhibits cancer stem cells and the metastatic capacity of triple-negative breast cancer cell lines by the simultaneous targeting of epithelial-to-mesenchymal transition, Wnt/ $\beta$-catenin and TGF $\beta$ signaling pathways. Eur. J. Nutr. 58, 3207-3219 (2019).

26. Bruna, A. et al. TGFbeta induces the formation of tumour-initiating cells in claudin-low breast cancer. Nat. Commun. 3, 1055 (2012).

27. Gomez-Puerto, M. C., Iyengar, P. V., García de Vinuesa, A., Ten Dijke, P. \& Sanchez-Duffhues, G. Bone morphogenetic protein receptor signal transduction in human disease. J. Pathol. 247, 9-20 (2019).

28. Campos, B. et al. Differentiation therapy exerts antitumor effects on stem-like glioma cells. Clin. Cancer Res. 16, 2715 (2010).

29. Lange, C. \& Calegari, F. Cdks and cyclins link G1 length and differentiation of embryonic, neural and hematopoietic stem cells. Cell Cycle 9, 1893-1900 (2010).

30. Chen, K. et al. Endogenous cyclin D1 promotes the rate of onset and magnitude of mitogenic signaling via Akt1 Ser473 phosphorylation. Cell Rep. 32, 108151 (2020).

31. Fantl, V., Stamp, G., Andrews, A., Rosewell, I. \& Dickson, C. Mice lacking cyclin D1 are small and show defects in eye and mammary gland development. Genes Dev. 9, 2364-2372 (1995).

32. Filipits, M. et al. Association of p27 and cyclin D1 expression and benefit from adjuvant trastuzumab treatment in HER2-positive early breast cancer: a TransHERA study. Clin. Cancer Res. 24, 3079 (2018).

33. Pathria, G., Garg, B., Garg, K., Wagner, C. \& Wagner, S. N. Dual c-Jun N-terminal kinase-cyclin D1 and extracellular signal-related kinase-c-Jun disjunction in human melanoma. Br. J. Dermatol. 175, 1221-1231 (2016).

34. Qie, S. \& Diehl, J. A. Cyclin D1, cancer progression, and opportunities in cancer treatment. J. Mol. Med. 94, 1313-1326 (2016).

35. Fusté, N. P. et al. Cytoplasmic cyclin D1 regulates cell invasion and metastasis through the phosphorylation of paxillin. Nat. Commun. 7, 11581 (2016).

36. Choi, $Y$. J. et al. The requirement for cyclin $D$ function in tumor maintenance. Cancer Cell 22, 438-451 (2012).

37. Dai, M. et al. Cyclin D1 cooperates with p21 to regulate TGFbeta-mediated breast cancer cell migration and tumor local invasion. Breast Cancer Res. 15, R49 (2013).

38. Dai, M. et al. CDK4 regulates cancer stemness and is a novel therapeutic target for triple-negative breast cancer. Sci. Rep. 6, 35383 (2016).

39. Duerr, E. M. et al. Oncogenic KRAS regulates BMP4 expression in colon cancer cell lines. Am. J. Physiol. Gastrointest. liver Physiol. 302, G1223-G1230 (2012).

40. Neve, R. M. et al. A collection of breast cancer cell lines for the study of functionally distinct cancer subtypes. Cancer Cell 10, 515-527 (2006).

41. Chen, E. Y. et al. Enrichr: interactive and collaborative HTML5 gene list enrichment analysis tool. BMC Bioinforma. 14, 128 (2013).

42. Kuleshov, M. V. et al. Enrichr: a comprehensive gene set enrichment analysis web server 2016 update. Nucleic Acids Res. 44, W90-W97 (2016).

43. Siegel, P. M. \& Massagué, J. Cytostatic and apoptotic actions of TGF- $\beta$ in homeostasis and cancer. Nat. Rev. Cancer 3, 807-820 (2003).

44. Minn, A. J. et al. Distinct organ-specific metastatic potential of individual breast cancer cells and primary tumors. J. Clin. Investig. 115, 44-55 (2005).

45. Cailleau, R., Young, R., Olive, M. \& Reeves, W. J. Jr. Breast tumor cell lines from pleural effusions. J. Natl Cancer Inst. 53, 661-674 (1974).

46. Gillett, C. et al. Amplification and overexpression of cyclin D1 in breast cancer detected by immunohistochemical staining. Cancer Res. 54, 1812-1817 (1994). 
47. Al-Hajj, M., Wicha, M. S., Benito-Hernandez, A., Morrison, S. J. \& Clarke, M. F. Prospective identification of tumorigenic breast cancer cells. Proc. Natl Acad. Sci. USA 100, 3983 (2003).

48. Liu, F. et al. Prolactin/Jak2 directs apical/basal polarization and luminal linage maturation of mammary epithelial cells through regulation of the Erk1/2 pathway. Stem Cell Res. 15, 376-383 (2015).

49. Ringnér, M., Fredlund, E., Häkkinen, J., Borg, Å. \& Staaf, J. GOBO: gene expression-based outcome for breast cancer online. PLOS ONE 6, e17911 (2011).

50. Koboldt, D. C., Fulton, R., Mclellan, M. D. \& Schmidt, H. Comprehensive molecular portraits of human breast tumours. Nature 490, 61-70 (2012).

51. Meyer, M. J. et al. CCD44posCD49fhiCD133/2hi defines xenograft-initiating cells in estrogen receptor-negative breast cancer. Cancer Res. 70, 4624-4633 (2010).

52. Pece, S. et al. Biological and molecular heterogeneity of breast cancers correlates with their cancer stem. Cell Content Cell 140, 62-73 (2010).

53. Saygin, C., Matei, D., Majeti, R., Reizes, O. \& Lathia, J. D. Targeting cancer stemness in the clinic: from hype to hope. Cell Stem Cell 24, 25-40 (2019).

54. Nagy, Á., Lánczky, A., Menyhárt, O. \& Győrffy, B. Validation of miRNA prognostic power in hepatocellular carcinoma using expression data of independent datasets. Sci. Rep. 8, 9227 (2018).

55. Butti, R., Gunasekaran, V. P., Kumar, T. V. S., Banerjee, P. \& Kundu, G. C. Breast cancer stem cells: Biology and therapeutic implications. Int. J. Biochem. Cell Biol. 107, 38-52 (2019).

56. Batlle, E. \& Clevers, H. Cancer stem cells revisited. Nat. Med. 23, 1124-1134 (2017).

57. Dai, M. et al. A novel function for p21Cip1 and acetyltransferase p/CAF as critical transcriptional regulators of TGFbeta-mediated breast cancer cell migration and invasion. Breast Cancer Res. 14, R127 (2012).

58. Yin, J. J. et al. TGF-beta signaling blockade inhibits PTHrP secretion by breast cancer cells and bone metastases development. J. Clin. Investig. 103, 197-206 (1999).

59. Bassey-Archibong, B. I. et al. Kaiso depletion attenuates transforming growth factor- $\beta$ signaling and metastatic activity of triple-negative breast cancer cells. Oncogenesis 5, e208 (2016).

60. Iriondo, O. et al. TAK1 mediates microenvironment-triggered autocrine signals and promotes triple-negative breast cancer lung metastasis. Nat. Commun. 9 , 1994 (2018).

61. Artegiani, B., Lindemann, D. \& Calegari, F. Overexpression of cdk4 and cyclinD1 triggers greater expansion of neural stem cells in the adult mouse brain. J. Exp. Med. 208, 937-948 (2011).
62. Lange, C., Huttner, W. B. \& Calegari, F. Cdk4/cyclinD1 overexpression in neural stem cells shortens $\mathrm{G} 1$, delays neurogenesis, and promotes the generation and expansion of basal progenitors. Cell Stem Cell 5, 320-331 (2009).

63. Jeselsohn, $\mathrm{R}$. et al. Cyclin D1 kinase activity is required for the self-renewal of mammary stem and progenitor cells that are targets of MMTV-ErbB2 tumorigenesis. Cancer Cell 17, 65-76 (2010).

64. Malumbres, M. \& Barbacid, M. Cell cycle, CDKs and cancer: a changing paradigm. Nat. Rev. Cancer 9, 153-166 (2009).

65. Li, R. et al. Expression of cyclin D1 splice variants is differentially associated with outcome in non-small cell lung cancer patients. Hum. Pathol. 39, 1792-1801 (2008).

66. Millar, E. K. et al. Cyclin D1b protein expression in breast cancer is independent of cyclin D1a and associated with poor disease outcome. Oncogene 28, 1812-1820 (2009)

67. Musgrove, E. A., Caldon, C. E., Barraclough, J., Stone, A. \& Sutherland, R. L. Cyclin D as a therapeutic target in cancer. Nat. Rev. Cancer 11, 558-572 (2011).

68. Schmierer, B. \& Hill, C. S. TGFbeta-SMAD signal transduction: molecular specificity and functional flexibility. Nat. Rev. Mol. Cell Biol. 8, 970-982 (2007).

69. Wu, M. Y. \& Hill, C. S. Tgf-beta superfamily signaling in embryonic development and homeostasis. Dev. Cell 16, 329-343 (2009).

70. Zhang, L. et al. BMP4 administration induces differentiation of CD133+ hepatic cancer stem cells, blocking their contributions to hepatocellular carcinoma. Cancer Res. 72, 4276-4285 (2012).

71. Lombardo, Y. et al. Bone morphogenetic protein 4 induces differentiation of colorectal cancer stem cells and increases their response to chemotherapy in mice. Gastroenterology 140, 297-309 (2011).

72. Emma-Leena, A. \& Anne, K. Bone morphogenetic proteins in breast cancer: dual role in tumorigenesis? Endocr.-Relat. Cancer 17, R123-R139 (2010).

73. Bach, D.-H., Park, H. J. \& Lee, S. K. The dual role of bone morphogenetic proteins in cancer. Mol. Ther. Oncolytics 8, 1-13 (2017).

74. Sims, A. H., Howell, A., Howell, S. J. \& Clarke, R. B. Origins of breast cancer subtypes and therapeutic implications. Nat. Clin. Pract. Oncol. 4, 516-525 (2007).

75. Hachim, I. Y., Hachim, M. Y., Lopez, V. M., Lebrun, J. J. \& Ali, S. Prolactin receptor expression is an independent favorable prognostic marker in human breast cancer. Appl. Immunohistochem. Mol. Morphol. 24, 238-245 (2016).

76. Hachim, I. Y., Shams, A., Lebrun, J. J. \& Ali, S. A favorable role of prolactin in human breast cancer reveals novel pathway based gene signatures indicative of tumor differentiation and favorable patient outcome: prolactin-induced mammary differentiation program in breast cancer prognosis. Hum. Pathol. $\mathbf{5 3}$ 142-152 (2016).

77. Nouhi, Z. et al. Defining the role of prolactin as an invasion suppressor hormone in breast cancer cells. Cancer Res. 66, 1824-1832 (2006). 